\title{
SEMI-ACTIVE VIBRATION CONTROL OF LAMINATED COMPOSITE SANDWICH PLATE - AN EXPERIMENTAL STUDY
}

\begin{abstract}
In this study, the vibration analysis of fully and partially treated laminated composite Magnetorheological (MR) fluid sandwich plates has been investigated experimentally. The natural frequencies of fully and partially treated laminated composite MR fluid sandwich plates have been measured at various magnetic field intensities under two different boundary conditions. The variations of natural frequencies with applied magnetic field, boundary conditions and location of MR fluid pocket have been explored. Further, a comparison of natural frequencies of fully and partially treated MR fluid sandwich structure has been made at various magnetic field intensities.
\end{abstract}

\section{Introduction}

The vibration control is a major challenge in structures and dynamic systems. In order to increase the efficiency of the system, the structures are being manufactured using lightweight materials with a compromise on having a low inherent damping. Therefore, damping amplification is necessary to avoid resonance in the systems. Among the several methods used to control the excessive vibrations, surface damping treatments are the one of the most easiest and frequently used method particularly in the sheet metal applications (Baz and Ro [1], Nashif et al. [2]). Furthermore, a range of semi-active control systems have been used in the various structural vibration control applications which include the controllable fluids, ER fluid and MR fluid. They provide the enhanced damping properties with only minimal power requirement compared to active and passive systems due to their controllable rheology (Spencer and Nagarajaiah [3], See [4], Stanway et al. [5], Xu et al. [6]).

\footnotetext{
${ }^{1}$ School of Mechanical and Building Sciences, VIT University, Vellore - 632014, India; Email: rmanoharan@vit.ac.in
} 
The application of MR fluids have been increasingly used in the various semi-active damping control applications in the low to moderate frequency ranges, including automotive suspension (Han et al. [7]), structures (Pranoto et al. [8], Yao et al. [9]) and automotive damping applications (Lam and Liao [10]). Bunch of experimental and numerical research works are available in the field of dynamic analysis of complex composite structures (Kim et al. [11]), Pandit et al. [12]). However, only limited amount of research works are available in the field of vibration analysis of sandwich plate with controllable fluids. Therefore the structural sandwich system with controllable fluids is the key research area in engineering in the past few years.

Sandwich structures including ER and MR materials provide the distributed control force uniformly throughout the structure by the application of electric or magnetic field yielding controlled stiffness and damping properties. The dynamic characteristics of ER fluid sandwich structures were analyzed experimentally by Gandhi et al. [13] at various applied electric field and concluded that the damping ratio and the natural frequency of the system could be controlled by controlling the applied electric field and variation in thickness of ER fluid layer. Choi et al. [14]) investigated experimentally the free vibration responses of ER fluid sandwich structure. The stress-strain properties of MR-fluids such as storage moduli and loss moduli were calculated through laboratory experiments by Weiss et al. [15], Li et al. [16] under various magnetic field intensities. Yeh and Chen [17] investigated the vibration of a sandwich plate with ER fluid core using finite element method. The study concluded that the applied electric field alters the stiffness of the sandwich plate significantly. It was also shown that the natural frequency of the sandwich plate increases with the increase in the applied electric field and the resonant frequencies of sandwich plate decrease when the thickness of ER fluid core is increased. The dynamic stability of a sandwich plate with a constraining layer and ER fluid core were investigated by Yeh and Chen $[18,19]$ using finite element method and harmonic balance method. It was concluded that the stiffness of the sandwich plate increases with the increase in electric field level and constraining layer thickness. The vibration analysis of a fully and partially treated ER fluid sandwich beam with clamped - clamped end conditions was performed by Haiqing and King [20]. It was concluded that the natural frequency and loss factor of the sandwich plate depends on the length of the ER fluid layer.

Lot of research works have been evaluated in the field of dynamic analysis of sandwich structures with ER fluid core, but very limited number of research works are available in the field of sandwich structures with MR fluid core. Yalcintas and Dai [21,22] investigated the vibration control capabilities of adaptive structures based on MR and ER fluid under the application of different magnetic and electric field levels. It was concluded that the increment 
of natural frequencies were almost twice in MR fluid sandwich beam compared to that of with ER fluid sandwich beam. The dynamic responses of a MR fluid sandwich beam were investigated by Sun et al. [23] using energy approach and validated through experimental results. The vibration characteristics of a MR fluid based sandwich beam were investigated by $\mathrm{Hu}$ et al. [24] using DiTaranto sixth order partial differential equations. It was concluded that the natural frequencies and loss factors of the sandwich beam were increased by increasing the applied magnetic field. The vibration analysis of MR fluid cantilever sandwich beams were investigated experimentally by Lara-Prieto et al. [25] at various magnetic field intensities. The natural frequencies of MR fluid sandwich plate were analyzed under the effect of applied magnetic field intensities on the fully and partial sections of sandwich plate. Rajamohan et al. [26] investigated the fully treated multi-layered MR fluid sandwich beam using finite element method and Ritz formulations and its natural frequencies were validated through the experimental investigation of the MR fluid sandwich beam. The various dynamic properties of a partially treated MR fluid sandwich beam were investigated by Rajamohan et al. [27] using finite element formulation and validated by the experimental test. Further the modal strain energy approach was used to evaluate the influence of location of the MR fluid segments in a partially treated MR fluid sandwich beam by Rajamohan et al. [28]. The dynamic characterization of non-homogeneous MR fluids based multi-layer beam was investigated by Rajamohan et al. [29]. The free vibration responses of MR elastomer based sandwich structures were investigated by Yeh [30]. The natural frequencies and loss factors of the sandwich plate were calculated under various magnetic field intensities.

Manoharan et al. [31] investigated the vibration analysis of a laminated composite MR fluid sandwich plate using finite element formulation. It was concluded that the natural frequencies and loss factor of the sandwich plate could be controlled by controlling the applied magnetic fields, varying the MR fluid layer thickness and by changing the fiber angle orientation of the composite plate. The vibration analysis of a partially treated laminated composite MR fluid sandwich plate was investigated by Manoharan et al. [32]. It was concluded that the location and size of MR fluid pockets influence the natural frequencies and loss factor of the sandwich plate in addition to magnetic fields and boundary conditions. Even though many studies have focused on MR fluid based sandwich structures, the vibration analysis of fully and partially treated MR fluid based laminated composite structures are yet be explored in detail.

In the present study, the experimental investigations of fully and partially treated laminated composite MR fluid sandwich plate are performed. The natural frequencies of a fully and the partially treated laminated composite MR fluid sandwich plates are measured for various magnetic field intensities 
under two different boundary conditions. Also the effects of location of MR fluid pockets in the sandwich plate on the variation of natural frequencies are explored.

\section{Experimental investigation of fully and partially treated laminated composite MR fluid sandwich plate}

The fully and partially treated laminated composite MR fluid sandwich plates have been fabricated to investigate the natural frequencies and evaluate the influence of location of MR fluid pockets on the variation of natural frequencies of the sandwich plate. The top and bottom of the composite laminates were fabricated through hand layup technique. It consists of many stages; initially a release agent was applied to the selected mold to remove the finished product with good surface finish from the mold, and then the E-glass unidirectional dry fabric [Inter glass 92145] layers or plies were arranged on the mold to form a laminate stack. Epoxy resin [LY556] was applied to the dried plies after layup process completed and this process was repeated until the total thickness of laminate was reached. Each laminate consists of seven plies with fiber angle orientation of $\left[0^{\circ} / 90^{\circ} / 0^{\circ} / \overline{90}^{\circ}\right]_{s}$ unidirectional fibers. At the end of layup process a vacuum bag with breather assemblies were placed over the laminates in order to remove the excess resin from the laminates and distribute the resin uniformly. Further it was cured in an autoclave, in which the temperature starts rising from $3^{\circ} \mathrm{C}$ to $100^{\circ} \mathrm{C}$ and for every 3 minutes it increases by $3^{\circ} \mathrm{C}$ after that it was maintained at $100^{\circ} \mathrm{C}$ about 2 hours in order to increase the strength of the laminates particularly for the aircraft structural components. Also proper volume fractions were maintained throughout the manufacturing process to improve the strength of laminates. The fully and partially treated laminated composite MR fluid sandwich plate was fabricated using two thin glass fiber laminated strips arranged in the order of $\left(\left[0^{\circ} / 90^{\circ} / 0^{\circ} / \overline{90}{ }^{\circ}\right]_{s}\right.$ and $\left.\left[0^{\circ} / 90^{\circ} / 0^{\circ} / \overline{90^{\circ}}\right]_{s}\right)$, with the size of $(300 \mathrm{~mm} \times 50 \mathrm{~mm} \times 1.5 \mathrm{~mm})$ and MR fluid (1 mm thickness) core layer as shown in Fig. 1a. A high-strength natural rubber was applied around the edges of the top and bottom laminates by proper adhesives in order to maintain the uniform gap between the laminates and to contain the MR fluid in between top and bottom plates.

In the partially treated laminated composite MR fluid sandwich plate, the combination of two layers ( $1 \mathrm{~mm}$ thickness) viz., rubber layer and MR layer were considered for the fabrication of the sandwich plate. Two different specimens of a partially treated MR fluid sandwich plates were fabricated to investigate the effect of MR fluid pockets on the natural frequencies of the structures. In the first specimen, the MR fluid pocket is located at the center of the sandwich plate with the size of $150 \mathrm{~mm} \times 48 \mathrm{~mm} \times 1 \mathrm{~mm}$ as shown 


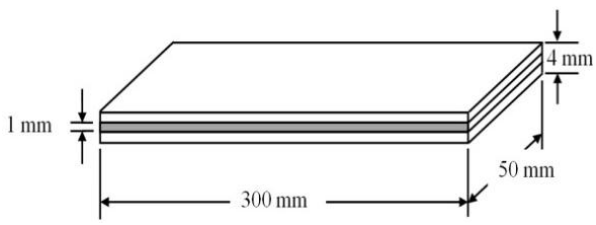

(a) Specimen block diagram for a fully treated laminated composite MR fluid sandwich plate

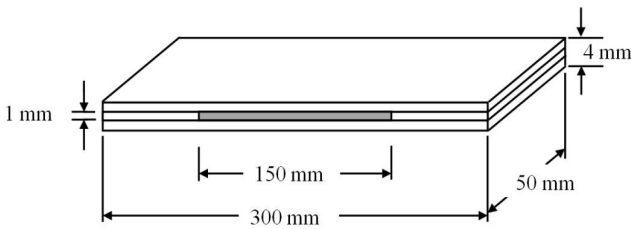

(b) The geometrical representation of the specimen of a partially treated laminated composite MR fluid sandwich plate with one pocket

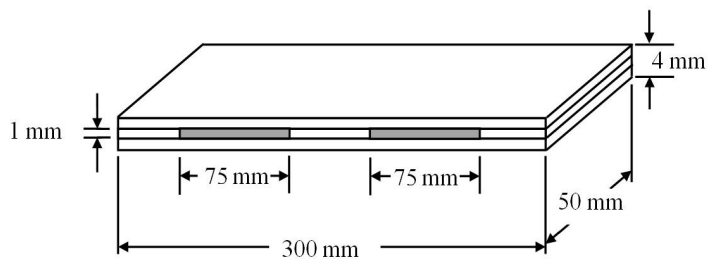

(c) The geometrical representation of the specimen of a partially treated laminated composite MR fluid sandwich plate with two pockets

Fig. 1. The fully and partially treated laminated composite MR fluid sandwich plate

in Fig. 1b, and the remaining areas of the middle layer of the sandwich plate was filled with rubber material. The second specimen consists of two MR fluid pockets located at a distance of $50 \mathrm{~mm}$ from both the ends with the size of $75 \mathrm{~mm} \times 48 \mathrm{~mm} \times 1 \mathrm{~mm}$ as shown in Fig. 1c, in which the rubber materials occupied the remaining area of core layer. The total mass of the MR fluids was maintained as identical in both specimens. After that, two small holes were drilled (near clamping region) on the top laminates of fully and partially treated sandwich plate to inject the fluid and remove the inside air from the sandwich plate. After injecting the MR fluids, both the holes were sealed properly.

A final form of fully and partially treated laminated composite MR fluid sandwich plate $\left(\left[0^{\circ} / 90^{\circ} / 0^{\circ} / \overline{90^{\circ}}\right]_{s} /\right.$ Core layer/ $\left.\left[0^{\circ} / 90^{\circ} / 0^{\circ} / \overline{90}{ }^{\circ}\right]_{s}\right)$ was clamped in the steel fixture. The test data is measured under two different end conditions including clamped $(\mathrm{C})$ and free $(\mathrm{F})$ along the edges of the plate. The two different boundary conditions namely CFCF and CFFF are considered in this experiment starting from the left end of the sandwich plate on counter clockwise direction. Permanent magnets were used to generate the uniform magnetic field over the surfaces of the sandwich plate. The fully and partially treated laminated composite MR fluid sandwich plate with complete experimental setup and schematic layout are shown in Fig. 2. Roving hammer (Impulse Force Hammer-086C03) method was used to accelerate the sandwich plate and an uniaxial accelerometer fixed on the top surface of the MR fluid sandwich plate measures the acceleration of sandwich plate due to excitation. A 4 channel Data Acquisition System (Model No. ATA-DAQ042451) was used to convert the 


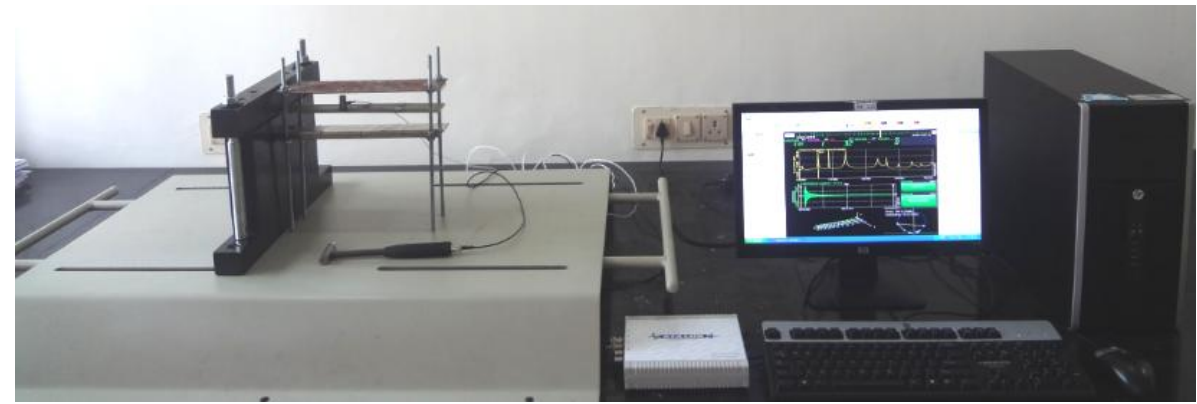

(a) Photograph of the experimental setup

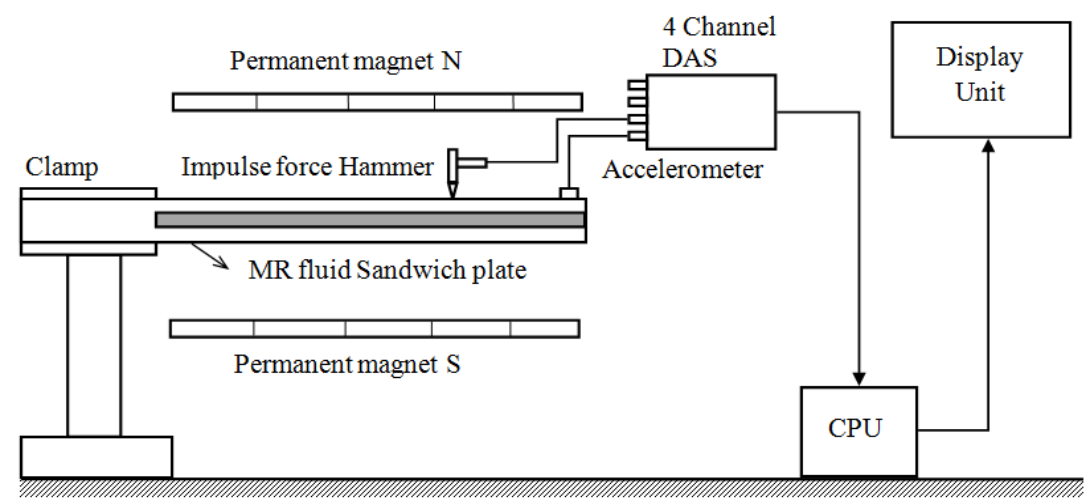

(b) Block diagram of the experimental setup of a clamped free (CFFF) fully treated laminated composite MR fluid sandwich plate

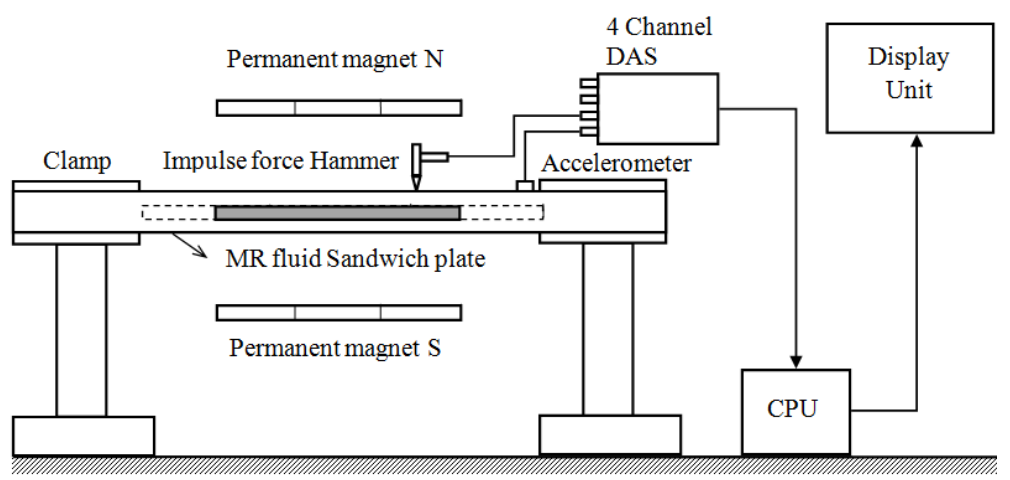

(c) Block diagram of the experimental setup

Fig. 2. The fully and partially treated laminated composite MR fluid sandwich plate

acceleration signals to frequency response function. The permanent magnets were arranged in vertical position with respect to the surface of sandwich plate. Gauss meter was used to measure the magnetic field intensity near the surfaces of sandwich plate. The natural frequencies of the MR fluid sandwich plate were 
measured (without magnetic field and with magnetic field) subsequently from the peaks in the frequency response function under three different magnetic field intensities as $0 G, 150 \mathrm{G}$ and $250 \mathrm{G}$. The vibration response could not be performed under higher magnetic field intensities because the available clearance between the magnets and the plate were very small, which produces repetitive locking of the sandwich plate with the magnets.

The complex shear modulus of MR fluid (MRHCCS4-B) was measured at Central Glass and Ceramic Research Institute (CGCRI) - Kolkata using MR Rheometer (plate and plate geometry - PP20/MRD \& Anton Paar Physica MCR-301). Experimental test was conducted at $250 \mathrm{C}$ and the flow characterization of the MR fluid sample was measured between 0 to $40 \mathrm{~Pa}$ controlled stress and 1 to $100 \%$ controlled strain. The variation of shear modulus $\left(G^{\prime}\right)$ and loss modulus $\left(G^{\prime \prime}\right)$ were obtained at three different magnetic field intensities at $0,0.25$ and $0.5 \mathrm{~T}$. The relations of shear modulus and loss modulus are expressed by the following second-order polynomial equations with respect to the magnetic field intensity $(G)$.

$$
\begin{gathered}
G^{\prime}=-0.05035 G^{2}+428.355 G+858.8 \\
G^{\prime \prime}=-0.057 G^{2}+452105 G+848.35
\end{gathered}
$$

where $G$ is the magnetic field intensity in Gauss.

The complex shear modulus $\left(G^{*}\right)$ of the MR material can be expressed as follows

$$
G^{*}=G^{\prime}+j G^{\prime \prime}
$$

where $G^{\prime}$ is the storage modulus, $G^{\prime \prime}$ is the loss modulus and $j=\sqrt{-1}$.

The material properties of E-glass unidirectional fibers with epoxy resins (LY0556) evaluated using rule of mixture and the geometrical properties considered for the experiments are: thickness of top $\left(h_{t}\right)$ and bottom $\left(h_{b}\right)$ laminate $=1.5 \mathrm{~mm}$, thickness of core $\left(h_{c}\right)=1 \mathrm{~mm}$, density of top $\left(\rho_{t}\right)$ and bottom $\left(\rho_{b}\right)$ laminate $=1779.34 \mathrm{~kg} / \mathrm{m}^{3}$, density of MR fluid $\left(\rho_{c f}\right)=2812 \mathrm{~kg} / \mathrm{m}^{3}$, density of rubber $\left(\rho_{c r}\right)=910 \mathrm{~kg} / \mathrm{m}^{3}$, Young's modulus of laminate along fiber direction $E_{1}=31.446 \mathrm{GPa}$, Young's modulus of laminate transverse to the fiber direction $E_{2}=7.435 \mathrm{GPa}$, major Poisson's ratio of laminate $v_{12}=0.2424$, minor Poisson's ratio of laminate $v_{21}=0.0573$, in-plane shear modulus of laminate $G_{12}=2.887 \mathrm{GPa}$.

Table 1 shows the effect of magnetic field intensity on the natural frequencies of a fully treated laminated composite MR fluid sandwich plate under clamped free (CFFF) and clamped free-clamped free (CFCF) end conditions. The results are presented for first three modes at three different magnetic fields. From the results it can be observed that the natural frequencies increases with increase in the applied magnetic fields, irrespective of all the modes and the 
The natural frequencies of fully treated laminated composite MR fluid sandwich plate measured experimentally under CFFF and CFCF boundary conditions

\begin{tabular}{|c|c|c|c|}
\hline \multirow{2}{*}{$\begin{array}{l}\text { Boundary } \\
\text { condition }\end{array}$} & \multirow{2}{*}{$\begin{array}{l}\text { Magnetic field } \\
\text { intensity }(G)\end{array}$} & \multirow{2}{*}{ Mode } & Natural frequencies $(\mathrm{Hz})$ \\
\hline & & & Measured \\
\hline \multirow{9}{*}{ CFFF } & \multirow{3}{*}{0} & 1 & 21.06 \\
\hline & & 2 & 110.01 \\
\hline & & 3 & 266.42 \\
\hline & \multirow{3}{*}{150} & 1 & 21.10 \\
\hline & & 2 & 110.67 \\
\hline & & 3 & 267.82 \\
\hline & \multirow{3}{*}{250} & 1 & 21.14 \\
\hline & & 2 & 111.10 \\
\hline & & 3 & 268.02 \\
\hline \multirow{9}{*}{$\mathrm{CFCF}$} & \multirow{3}{*}{0} & 1 & 95.97 \\
\hline & & 2 & 224.84 \\
\hline & & 3 & 403.09 \\
\hline & \multirow{3}{*}{150} & 1 & 96.05 \\
\hline & & 2 & 225.52 \\
\hline & & 3 & 407.02 \\
\hline & \multirow{3}{*}{250} & 1 & 96.33 \\
\hline & & 2 & 226.31 \\
\hline & & 3 & 410.07 \\
\hline
\end{tabular}

boundary conditions considered. This can be related to the fact that the shear modulus of MR material increases with increase in the applied magnetic field level as evident from Eq. 1 which obviously increases the stiffness of the structure. Further it is observed that the CFCF and CFFF boundary conditions yield the highest and lowest natural frequencies, respectively at all the modes considered. This is due to the fact that clamping at both the ends conditions of MR fluid sandwich plate yields higher stiffness compared to clamping at one side of the sandwich plate. It is also to be noted that the variations among measured natural frequencies are smaller due to application of the low magnitude of magnetic field intensity.

Table 2 shows the measured natural frequencies of the two different configurations of a partially treated laminated composite MR fluid sandwich plate with the various applied magnetic field under CFCF boundary conditions. It can be observed that as expected the natural frequencies increases with increase in applied magnetic field intensities, irrespective of the entire mode considered. However, it can also be noticed that the variation of natural frequencies with applied magnetic field is minimal because of the smaller size of MR fluid pocket (partial treatment of MR fluid) as well as the lower magnitude 
SEMI-ACTIVE VIBRATION CONTROL OF LAMINATED COMPOSITE SANDWICH PLATE ...

Table 2.

The natural frequencies of the partially treated laminated composite MR fluid sandwich plate measured experimentally under CFCF boundary conditions

\begin{tabular}{|c|c|c|c|c|}
\hline \multirow{2}{*}{$\begin{array}{l}\text { Boundary } \\
\text { condition }\end{array}$} & \multirow{2}{*}{$\begin{array}{l}\text { Magnetic field } \\
\text { intensity }(G)\end{array}$} & \multirow[t]{2}{*}{ Mode } & $\begin{array}{c}\text { Natural frequencies }(\mathrm{Hz}) \\
\text { 1-MR Pocket }\end{array}$ & $\begin{array}{c}\text { Natural frequencies }(\mathrm{Hz}) \\
\text { 2-MR Pocket }\end{array}$ \\
\hline & & & Measured & Measured \\
\hline \multirow{9}{*}{ CFFF } & \multirow{3}{*}{0} & 1 & 111.82 & 108.53 \\
\hline & & 2 & 282.89 & 290.54 \\
\hline & & 3 & 485.18 & 494.26 \\
\hline & \multirow{3}{*}{150} & 1 & 112.31 & 108.85 \\
\hline & & 2 & 283.90 & 290.90 \\
\hline & & 3 & 487.20 & 495.32 \\
\hline & \multirow{3}{*}{250} & 1 & 112.62 & 109.91 \\
\hline & & 2 & 284.12 & 291.21 \\
\hline & & 3 & 487.91 & 496.12 \\
\hline
\end{tabular}

of the applied magnetic field. Further it can be seen that the location of MR fluid pockets influences the natural frequencies of the MR fluid sandwich plate apart from the applied magnetic field and the boundary conditions. Furthermore, the natural frequencies of a partially treated MR fluid sandwich plate are higher than those of fully treated sandwich plate. This is due to the fact that as the density of MR fluid $\left(\rho_{c f}=2812 \mathrm{~kg} / \mathrm{m}^{3}\right)$ is higher than the rubber material $\left(\rho_{c r}=910 \mathrm{~kg} / \mathrm{m}^{3}\right)$ considered in the analysis, the replacement of MR fluid with rubber materials reduces the mass of the structure which leads to increase in natural frequency. This confirms the effective vibration control in the application of partial treatment or partial regions of the large structure.

\section{Conclusions}

The vibration responses of fully and partially treated laminated composite MR fluid sandwich plates have been investigated experimentally. The effect of magnetic field on the variation of natural frequencies of fully and partially treated laminated composite MR fluid sandwich plates are analyzed for different configurations with three magnetic field intensities. The natural frequencies of MR fluid sandwich plate increases with the increase in applied magnetic field intensities irrespective of all the modes and the boundary conditions considered. Also, this analysis suggested that the natural frequency of the partially treated laminated composite MR fluid sandwich plate are strongly influenced by the location of MR fluid pockets in addition to the applied magnetic field intensity and boundary conditions. Therefore, it can be concluded that the application of partial treatment can be applied in the critical regions of the large structures in order to realize the vibration control using controllable MR fluids. 
Manuscript received by Editorial Board, August 28, 2015; final version, May 19, 2016.

\section{References}

[1] A. Baz and J. Ro. Optimum design and control of active constrained layer damping. Journal of Mechanical Design, 117(B):135-144, 1995.

[2] A.D. Nashif, D.I. Jones, and J.P. Henderson. Vibration damping. John Wiley \& Sons, 1985.

[3] B.F. Spencer Jr. and S. Nagarajaiah. State of the art of structural control. Journal of Structural Engineering, 129(7):845-856, 2003.

[4] H. See. Advances in electro-rheological fluids: materials, modelling and applications. Journal of Industrial and Engineering Chemistry, 10(7):1132-1145, 2004.

[5] R. Stanway, J.A. Rongong, and N.D. Sims. Active constrained-layer damping: a state-of-the-art review. Proceedings of the Institution of Mechanical Engineers, Part I: Journal of Systems and Control Engineering, 217(6):437-456, 2003.

[6] Y.L. Xu, W.L. Qu, and J.M. Ko. Seismic response control of frame structures using magnetorheological/electrorheological dampers. Earthquake Engineering \& Structural Dynamics, 29(5):557-575, 2000.

[7] Y.M. Han, J.Y. Jung, S.B. Choi, Y.T. Choi, and N.M. Wereley. Ride quality investigation of an electrorheological seat suspension to minimize human body vibrations. Proceedings of the Institution of Mechanical Engineers, Part D: Journal of Automobile Engineering, 220(2):139150, 2006.

[8] T. Pranoto, K. Nagaya, and A. Hosoda. Vibration suppression of plate using linear MR fluid passive damper. Journal of Sound and Vibration, 276(3):919-932, 2004.

[9] G.Z. Yao, F.F. Yap, G. Chen, W.H. Li, and S.H. Yeo. MR damper and its application for semi-active control of vehicle suspension system. Mechatronics, 12(7):963-973, 2002.

[10] A. H.F. Lam and W.H. Liao. Semi-active control of automotive suspension systems with magneto-rheological dampers. International Journal of Vehicle Design, 33(1-3):50-75, 2003.

[11] M.J. Kim and A. Gupta. Finite element analysis of free vibrations of laminated composite plates. International Journal of Analytical and Experimental Modal Analysis, 5(3):195-203, 1990.

[12] M.K. Pandit, S. Haldar, and M. Mukhopadhyay. Free vibration analysis of laminated composite rectangular plate using finite element method. Journal of Reinforced Plastics and Composites, 26(1):69-80, 2007.

[13] M.V. Gandhi, B.S. Thompson, and S.B. Choi. A new generation of innovative ultra-advanced intelligent composite materials featuring electro-rheological fluids: an experimental investigation. Journal of Composite Materials, 23(12):1232-1255, 1989.

[14] Y. Choi, A.F. Sprecher, and H. Conrad. Vibration characteristics of a composite beam containing an electrorheological fluid. Journal of Intelligent Material Systems and Structures, 1(1):91-104, 1990.

[15] K.D. Weiss, J.D. Carlson, and D.A. Nixon. Viscoelastic properties of magneto-and electrorheological fluids. Journal of Intelligent Material Systems and Structures, 5(6):772-775, 1994.

[16] W.H. Li, G. Chen, and S.H. Yeo. Viscoelastic properties of MR fluids. Smart Materials and Structures, 8(4):460-468, 1999.

[17] J.Y. Yeh and L.W. Chen. Vibration of a sandwich plate with a constrained layer and electrorheological fluid core. Composite Structures, 65(2):251-258, 2004.

[18] J.Y. Yeh and L.W. Chen. Dynamic stability of a sandwich plate with a constraining layer and electrorheological fluid core. Journal of Sound and Vibration, 285(3):637-652, 2005.

[19] J.Y. Yeh and L.W. Chen. Finite element dynamic analysis of orthotropic sandwich plates with an electrorheological fluid core layer. Composite Structures, 78(3):368-376, 2007. 
[20] G. Haiqing and L.M. King. Vibration characteristics of sandwich beams partially and fully treated with electro-rheological fluid. Journal of Intelligent Material Systems and Structures, 8(5):401-413, 1997.

[21] M. Yalcintas and H. Dai. Magnetorheological and electrorheological materials in adaptive structures and their performance comparison. Smart Materials and Structures, 8(5):560, 1999.

[22] M. Yalcintas and H. Dai. Vibration suppression capabilities of magnetorheological materials based adaptive structures. Smart Materials and Structures, 13(1):1, 2003.

[23] Q. Sun, J.X. Zhou, and L. Zhang. An adaptive beam model and dynamic characteristics of magnetorheological materials. Journal of Sound and Vibration, 261(3):465-481, 2003.

[24] B. Hu, D. Wang, P. Xia, and Q. Shi. Investigation on the vibration characteristics of a sandwich beam with smart composites-MRF. World Journal of Modelling and Simulation, 2(3):201-206, 2006.

[25] V. Lara-Prieto, R. Parkin, M. Jackson, V. Silberschmidt, and Z. Kęsy. Vibration characteristics of MR cantilever sandwich beams: experimental study. Smart Materials and Structures, 19(1):015005, 2009.

[26] V. Rajamohan, R. Sedaghati, and S. Rakheja. Vibration analysis of a multi-layer beam containing magnetorheological fluid. Smart Materials and Structures, 19(1):015013, 2009.

[27] V. Rajamohan, S. Rakheja, and R. Sedaghati. Vibration analysis of a partially treated multilayer beam with magnetorheological fluid. Journal of Sound and Vibration, 329(17):3451-3469, 2010.

[28] V. Rajamohan, R. Sedaghati, and S. Rakheja. Optimum design of a multilayer beam partially treated with magnetorheological fluid. Smart Materials and Structures, 19(6):065002-15, 2010.

[29] V. Rajamohan and M. Ramamoorthy. Dynamic characterization of non-homogeneous magnetorheological fluids based multi-layer beam. In Applied Mechanics and Materials, volume 110, pages 105-112. Trans Tech Publ, 2012.

[30] J.Y. Yeh. Vibration analysis of sandwich rectangular plates with magnetorheological elastomer damping treatment. Smart Materials and Structures, 22(3):035010, 2013.

[31] R. Manoharan, R. Vasudevan, and A.K. Jeevanantham. Dynamic characterization of a laminated composite magnetorheological fluid sandwich plate. Smart Materials and Structures, 23(2):025022, 2014.

[32] R. Manoharan, R. Vasudevan, and A.K. Jeevanantham. Vibration analysis of a partially treated laminated composite magnetorheological fluid sandwich plate. Journal of Vibration and Control, 2014. doi: 10.1177/1077546314532302.

\section{Półaktywne sterowanie drganiami płyty warstwowej z laminatu kompozytowego - studium eksperymentalne}

Streszczenie

W pracy przedstawiono studium eksperymentalne analizy wibracji płyty warstwowej z warstwą laminatu całkowicie lub częściowo wypełnioną ferropłynem reologicznym (MR). Częstotliwości drgań własnych warstwowej płyty $\mathrm{z}$ warstwą całkowicie lub częściowo zmodyfikowaną płynem MR mierzono przy różnych natężeniach pola magnetycznego i dla dwu różnych warunków brzegowych. Badano zmiany częstotliwości drgań własnych pod wpływem pola magnetycznego i wpływ warunków brzegowych i usytuowania kieszonek z płynem reologicznym. Ponadto, porównano częstotliwości drgań własnych struktur laminatu z częściową lub pełną warstwą płynu reologicznego przy różnych natężeniach pola magnetycznego. 